\title{
Analysis of long-term anatomic results of radical mastoidectomy
}

\author{
HORIA MOCANU ${ }^{1 *}$, ADELA-IOANA MOCANU ${ }^{2}$, GABRIELLA COADA $^{3}$, \\ ALEXANDRU BONCIU ${ }^{4}$, MIHAI-ADRIAN SCHIPOR ${ }^{5}$ and MARIAN RĂDULESCU ${ }^{6 *}$ \\ ${ }^{1}$ Department of ENT and HNS, Faculty of Medicine, 'Titu Maiorescu' University, 031593 Bucharest; \\ ${ }^{2}$ Department of ENT and HNS, Polimed Medical Center, 040067 Bucharest; ${ }^{3}$ Department of ENT and HNS, \\ 'Sf. Maria' Clinical Hospital, 011172 Bucharest; ${ }^{4}$ Department of ENT and HNS, \\ 'Dr. Carol Davila' Central Military Emergency University Hospital, 010825 Bucharest, Romania; \\ ${ }^{5}$ Technical University of Munich, Institute of Astronomical and Physical Geodesy, D-80333 Munich, Germany; \\ ${ }^{6}$ Department of ENT and HNS, 'Carol Davila' University of Medicine and Pharmacy, 020021 Bucharest, Romania
}

Received October 15, 2021; Accepted November 15, 2021

DOI: $10.3892 /$ etm.2021.11079

\begin{abstract}
A long-term, retrospective, non-controlled study was performed on the drainage results of mastoidectomy (both radical and modified radical) and the relevant statistical factors that could influence the anatomic outcome were defined. The present study took into consideration the same cohort of 200 patients we have communicated with before in our previous studies concerning the long-term functional results of mastoidectomy and long-term results of ossicular replacement with biovitroceramic prosthesis. The patients were clinically followed for the same period of 8.12 years. The drainage (anatomic) results, similar to previously published functional results, were defined by analytical function of the severity and the period of evolution of disease. The main goal was to define the situations and factors (presence of complications, type of disease, type of tympanic perforation or status of ossicular chain) that influenced the drainage results that could provide us with some type of anatomical prognosis. The follow-up started at the moment of complete epithelization for each cavity as time represents the main study comparison criteria. Drainage failure was assessed by the number of otorrhea episodes. It was concluded that practically and ideally, a maximum of $84 \%$ of the mastoid and petrous cells can be cleaned out. The results of $78 \%$ drainage success are congruent to this theory. The remaining $16 \%$ of cells may contain irreversible lesions.
\end{abstract}

Correspondence to: Dr Adela-Ioana Mocanu, Department of ENT and HNS, Polimed Medical Center, Calea Văcărești 280, 040067 Bucharest, Romania

E-mail: adela.ioana.mocanu@gmail.com

*Contributed equally

Key words: middle ear, mastoidectomy, otitis media, attic, cholesteatoma, anatomic results, drainage, quality of life

\section{Introduction}

Radical mastoidectomy has been performed as early as the 16th century and its main purpose is to eradicate chronic otitis media or cholesteatoma and create anatomical conditions to prevent reoccurrence (1). By anatomic (drainage) results, it is understood that removing lesions, maintaining unobstructed drainage and reducing complications both intra and extracranial is required to obtain a reliable, safe and disease-free middle-ear $(2,3)$. The usual surgical approach is represented by canal wall-up (CWU) and the canal wall-down (CWD) mastoidectomies. Intact canal wall procedures, such as CWU, are known to be associated with high risk of recurrence and residual inflammatory lesions (4), but at the same time they preserve much of the anatomy, while radical and radical modified mastoidectomy techniques, such as CWD, allow for good visualization of structures and consequently proportional good chances of complete removal of lesions (5). It is however certain that while pursuing anatomic results (complete drainage and cavity cleanliness), the functional results are occasionally poor (hearing is destroyed or at least gravely impaired) as we have stated in our previous two studies involving the same cohort of patients $(6,7)$. We found that recreating the continuity of the ossicular chain (OC) is paramount both for functional and anatomical results in middle ear surgery $(8,9)$, but useless without a well-performed mastoidectomy. These aspects should not be taken lightly since hearing loss represents one of the most serious afflictions worldwide (World Health Organization estimates that between 65 and 330 million individuals suffer from some form of middle ear suppuration and 50\% of them suffer from hearing impairment) (10). Other environmental and clinical risk factors cannot be ruled out and the clinician must always bear in mind that a situation where genetic predisposition is augmented by environmental factors is common and even more complicated (10).

Thus, the aim of the present study was to determine to what extent can a completely and permanently 'dry ear' be expected and identify the potential parameters that most influence the drainage results. 


\section{Patients and methods}

Patient selection. The same cohort of patients used in our previous studies on the long-term functional results of mastoidectomy and long-term results of ossicular replacement with biovitroceramic prosthesis $(6,7)$ were used in the present study. We find it important to be able to compare functional, anatomical and reconstructive results for the same patients, using the same surgical techniques and communicate long-term data. This retrospective non-controlled study took into consideration the same random selection of 200 long-term patients with both radical CWD and modified radical mastoidectomy (MRM), performed over a 3-year period. The techniques for both types of surgery are well-known and described in literature $(5,11,12)$. The initial cohort was comprised of 209 patients, of which nine died (eight of causes non-related to middle-ear disease, one directly related to middle-ear disease after otogenic brain abscess). The basic statistical criteria for the selection were post-operative time span. Data analysis began in 2004, giving a post-operative follow-up period of 8.12 years for the entire cohort from the moment of surgery, and 7.86 years from the time of complete epithelization of cavity, which allows us to consider it as long-term evaluation. All patients were clinically evaluated (microscope otoscopy), both before the surgery and after the surgery as follows: i) Monthly for the first 6 months post-operative; ii) every 2 months for the next 6 months (up to 1 year, corresponding to the moment of complete epithelization of cavity for $>80 \%$ of cases); iii) every 6 months in the 2nd year; iv) every 8 months for the 3rd and 4th year post-op; and v) every 12-16 months for the 5th year post-op and also at any other occurrent otorrhea episode. The follow-up of drainage results started from the moment of complete epithelization of cavity for each patient (Figs. 1 and 2).

It is also noteworthy to point out the shift in the age group distribution of patients that follows the long-term study of a cohort (Fig. 3). Age was defined at the time of surgery as: Physical time, duration of evolution, aging (progressive degradation of function at different rates), an unstoppable increase in damaged cells proportion, increase of degree or intensity of disease, rise of hearing thresholds-all of these being included in a formalized model (physical-mathematical model).

The distribution of sex and environment is presented in absolute frequencies in Fig. 4.

Paraclinical diagnosis. Radiological examination was also performed for all patients (bilateral X-ray in Schuller's view) with high degree of sensitivity and specificity for mastoid diagnosis. A total of $55 \%(n=31)$ of the cholesteatoma cases and $61 \%(n=28)$ of previously operated ears could be correctly diagnosed (Fig. 5).

The main goal of the present study was to define the situations and factors that influence the drainage results of mastoidectomy that could provide us with some type of anatomical prognosis. Based on the selection criteria of the studied group and by performing statistical analysis of the correlation of anatomic results and statistically significant variables, pertinent conclusions could be formulated regarding the drainage success rate of mastoidectomy.

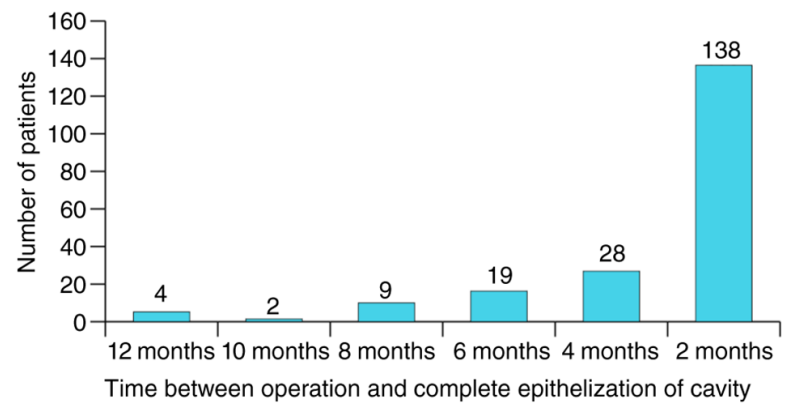

Figure 1. Patient distribution associated with the period of complete epithelization of cavity.

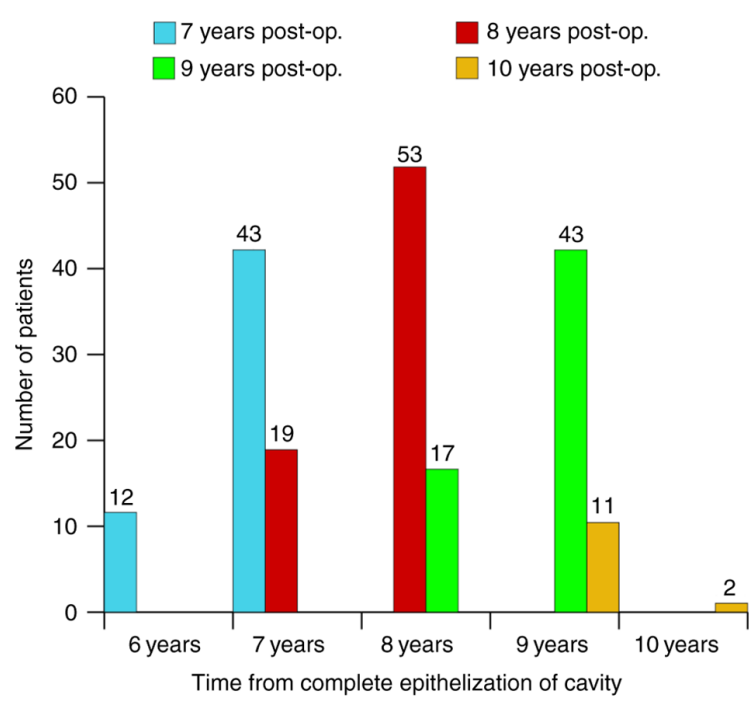

Figure 2. Patient distribution associated with the timespan from operation and from the moment of complete epithelization of cavity.

Statistical analysis. Although largely clinical, this study also included some statistical analysis, including creating Microsoft Excel databases and attributing codes to facilitate data analysis using Excel (Microsoft Corporation) and SPSS v15 (SPSS, Inc.). Factors such as age of patient, presence of cholesteatoma, stage of disease etc., were associated with the functional results of mastoidectomy. Data were synthesized as percentage, mean values and standard deviation. $\mathrm{P}<0.05$ was considered to indicate a statistically significant difference. Parametric (unpaired Student's t-test) or non-parametric (Mann-Whitney) tests were also applied.

\section{Studied variables}

Pre-surgery variables. Pre-surgery variables were as follows: i) Age group, $0-10$ years $(n=1), 11-20$ years $(n=4), 21-30$ years $(n=56), 31-40$ years $(n=45), 41-50$ years $(n=49), 51-60$ years $(n=27), 61-70$ years $(n=15)$ or $71-80$ years $(n=3)$; ii) clinical stage of disease, complicated $(n=45)$ or not complicated $(n=155)$; iii) type of disease, cholesteatoma $(n=56)$ or noncholesteatoma $(n=144)$; and iv) type of tympanic membrane perforation, marginal $(n=75)$ or central $(n=125)$.

Intraoperative data. Intraoperative data variables were as follows: i) Type of mastoidectomy, modified radical $(n=125)$ 


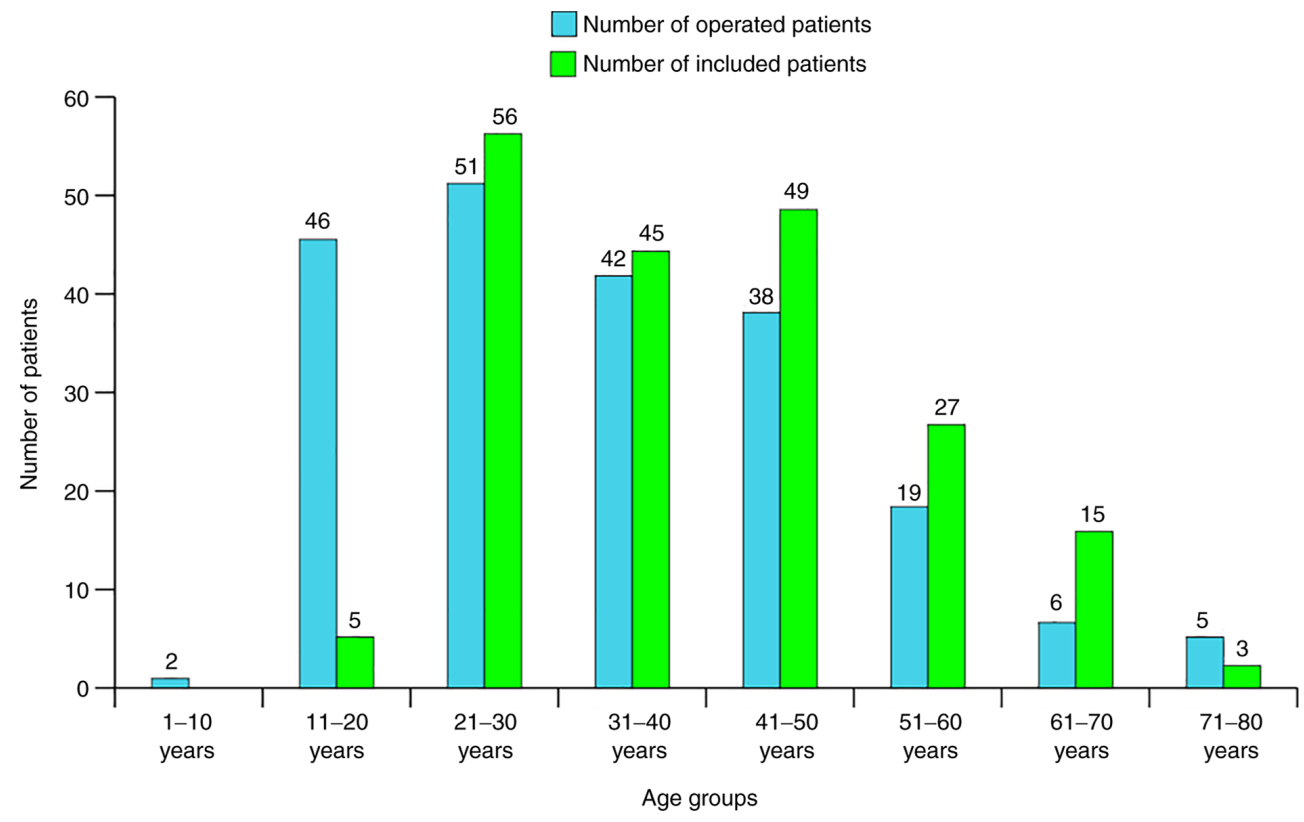

Figure 3. Age group distribution (absolute frequencies) at the time of operation and at the moment of complete epithelization of cavity.

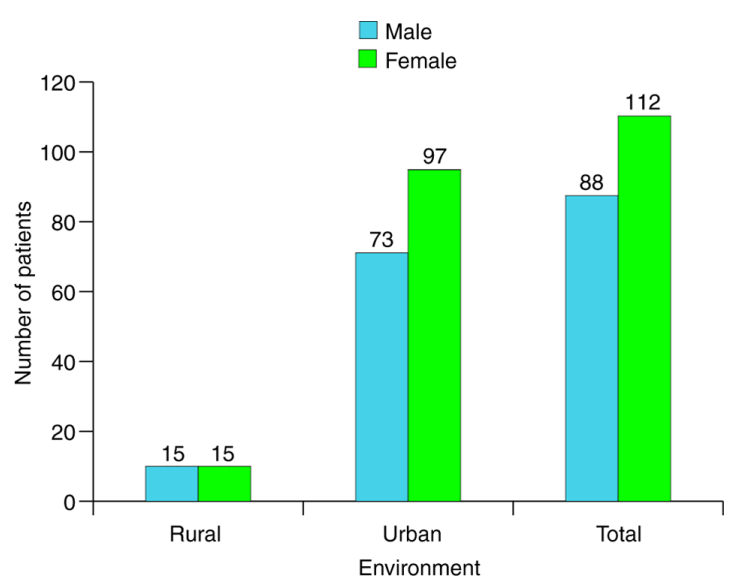

Figure 4. Patient distribution according to sex and environment.

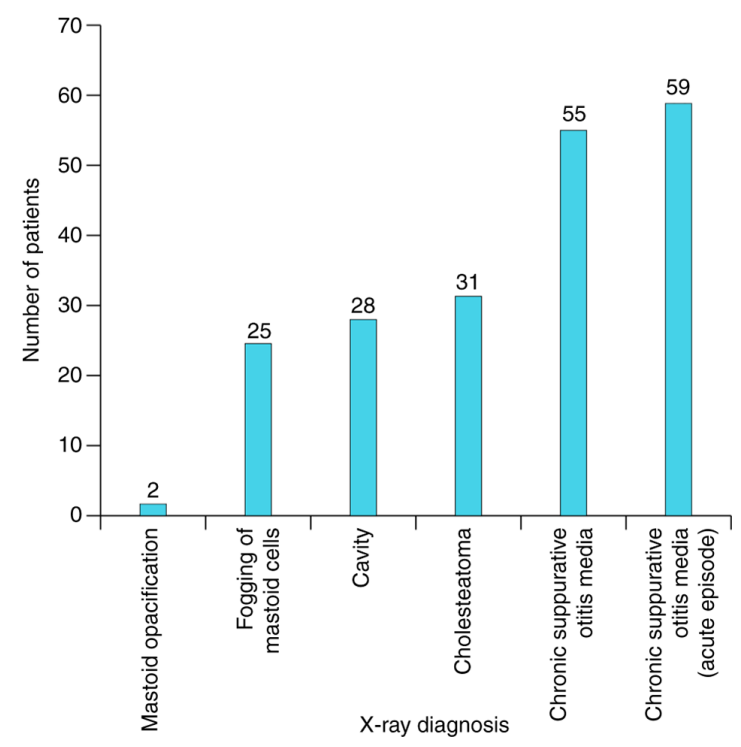

Figure 5. Patient distribution according to radiological diagnosis.

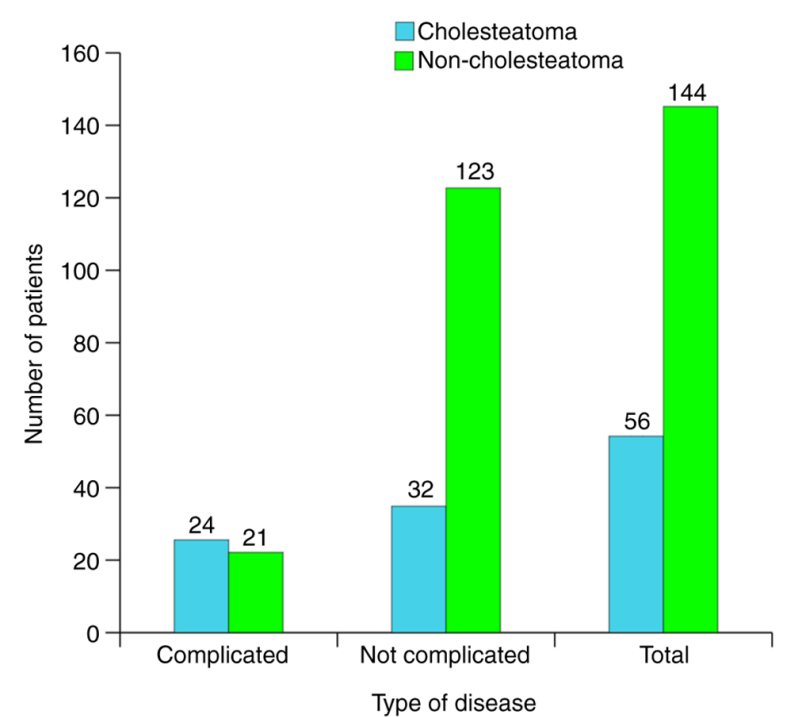

Figure 6. Patient distribution according to the type of disease.

or radical $(n=75)$; ii) OC status, absent $(n=13)$, complete and mobile $(n=27)$, complete and fixed $(n=25)$, or interrupted $(n=135)$; and iii) total lesion score, 0-19 $(n=170), 20-39(n=13)$, $40-59(n=5), 60-79(n=5), 80-99(n=4), 100-119(n=2)$ or 140-159 (n=1).

Follow-up data. Follow-up data variables were as follows: i) Period for complete epithelization of cavity, 2 months, 1 year, 2 years, 3-4 years or 8 years; ii) cavity self-cleansing, present or absent; and iii) mastoidectomy result (drainage effect), failure or success.

\section{Results and Discussion}

Successful mastoidectomy was defined in the present study as the total absence of otorrhea episodes after total epithelization 
Table I. Absolute and relative frequencies of complications.

\begin{tabular}{|c|c|c|}
\hline Type of complication & Number of patients ${ }^{\mathrm{a}}$ & Relative frequency, $\%$ \\
\hline MCF internal cortical dehiscence & 39 & 20.0 \\
\hline Vertigo $^{\mathrm{b}}$ & 37 & 18.5 \\
\hline Fallopian canal dehiscence & 24 & 12.0 \\
\hline Deafness $^{b}$ & 22 & 11.0 \\
\hline Macroscopic labyrinth lesion & 17 & 8.5 \\
\hline Sigmoid cortical dehiscence & 15 & 7.5 \\
\hline PCF internal cortical dehiscence & 14 & 7.0 \\
\hline Fungal pachymeningitis & 14 & 7.0 \\
\hline Facial paralysis ${ }^{\mathrm{b}}$ & 11 & 5.5 \\
\hline Exteriorization of suppurative process ${ }^{b}$ & 11 & 5.5 \\
\hline Lateral semicircular canal fistula & 11 & 5.5 \\
\hline Sudden hearing loss ${ }^{\mathrm{b}}$ & 8 & 4.0 \\
\hline Macroscopic facial nerve lesion & 7 & 3.5 \\
\hline Sigmoid sinus phlebitis & 6 & 3.0 \\
\hline Labyrinthine fistula & 6 & 3.0 \\
\hline Posterior semicircular canal fistula & 5 & 2.5 \\
\hline Extradural abscess PCF & 3 & 1.5 \\
\hline Extradural abscess MCF & 2 & 1.0 \\
\hline Acute meningitis & 1 & 0.5 \\
\hline Mandibular fossa abscess (extra-articular) & 1 & 0.5 \\
\hline Cerebellum abscess & 1 & 0.5 \\
\hline
\end{tabular}

${ }^{\mathrm{a} A b s o l u t e}$ frequency; ${ }^{\text {b } C l i n i c a l ~ d i a g n o s i s . ~ M C F, ~ m e d i a l ~ c r a n i a l ~ f o s s a ; ~} \mathrm{PCF}$, posterior cranial fossa.

Table II. Lesion scores for complications.

\begin{tabular}{|c|c|c|}
\hline Intra-operative lesion & Attributed score & Ordinal of scores \\
\hline Cerebellum abscess & 20 & 1 \\
\hline Cerebral abscess & 20 & 1 \\
\hline Sigmoid sinus thrombophlebitis & 15 & 2 \\
\hline Extradural abscess MCF & 10 & 3 \\
\hline Extradural abscess PCF & 10 & 3 \\
\hline Acute meningitis & 10 & 3 \\
\hline Sigmoid sinus periphlebitis & 10 & 3 \\
\hline Total lysis of stapes footplate & 9 & 4 \\
\hline Lateral semicircular canal fistula & 9 & 4 \\
\hline Posterior semicircular canal fistula & 9 & 4 \\
\hline Labyrinthine fistula & 9 & 4 \\
\hline Macroscopic labyrinth lesion & 9 & 4 \\
\hline Fungal pachymeningitis & 9 & 4 \\
\hline Mandibular fossa abscess (extra-articular) & 8 & 5 \\
\hline MCF internal cortical dehiscence & 8 & 5 \\
\hline PCF internal cortical dehiscence & 8 & 5 \\
\hline Sigmoid cortical dehiscence & 8 & 5 \\
\hline Exteriorization of suppurative process ${ }^{\mathrm{a}}$ & 8 & 5 \\
\hline Fallopian canal dehiscence & 7 & 6 \\
\hline Macroscopic facial nerve lesion & 7 & 6 \\
\hline Facial paralysis ${ }^{\mathrm{a}}$ & 7 & 6 \\
\hline
\end{tabular}

${ }^{\mathrm{a}}$ Clinical diagnosis. MCF, medial cranial fossa; PCF, posterior cranial fossa. 


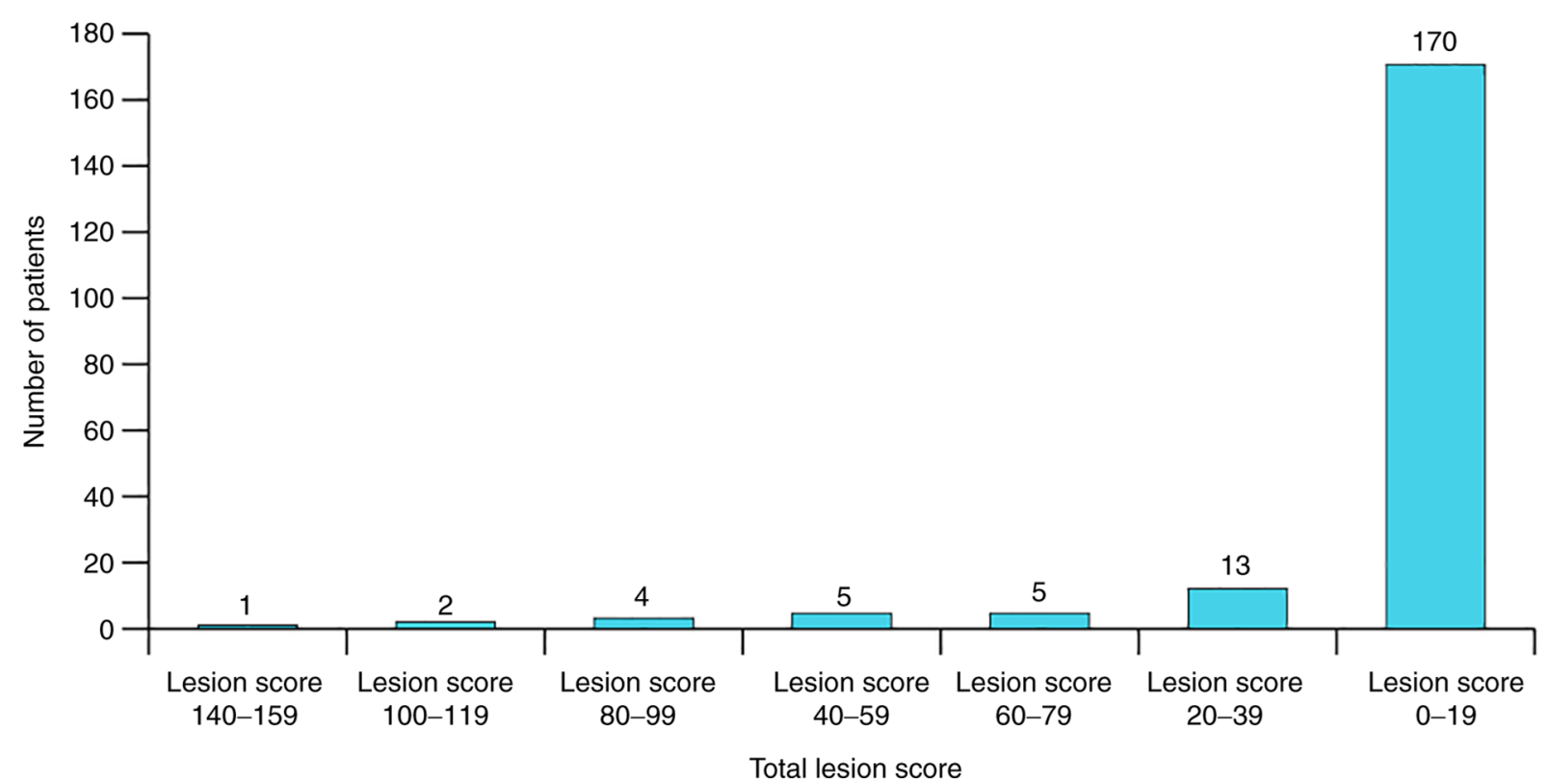

Figure 7. Patient distribution according to total lesion score.

of cavity and by failure of the presence of at least one such episode. According to this definition the global drainage results of mastoidectomy could be appreciated in this study. What remained to be determined was to what extent could a completely and permanently 'dry ear' be expected, and to identify the potential parameters that most influenced the outcome.

Fig. 6 shows the distribution of patients associated with the type of disease and presence of complications. A total of $23 \%$ of patients $(n=45)$ presented with complications, but it was observed that cholesteatoma cases had a $43 \%$ rate of complications, whilst non-cholesteatoma cases had only $16 \%$.

Complications of disease have predictive clinical significance, which can be hierarchized (Table I). For obtaining an exact quantitative lesion profile (including all other lesions except those of the middle-ear mucosa, protympanum, tympanic cavity, aditus to mastoid antrum, mastoid bone and petrous apex), points were assigned (directly proportional to presumed gravity) for each type of lesion (Table II). Vertigo for instance was 3.36 times more significant than facial paralysis and exteriorization and 4.56 times less significant than sudden hearing loss (Tables I and II). It was considered most surprising that the proportion of middle cranial fossa dehiscence was the largest, and equally surprising was the proportion of Fallopian canal dehiscence and its ratio to clinically documented facial paralysis. This meant that patients could be categorized by this lesion score, as seen in Fig. 7.

Another important parameter studied was the type of exteriorization of the suppurative mastoid disease. The relative frequency of these exteriorizations is presented in Fig. 8 and yielded noteworthy results. Gellé's fistula (collapse of the posterosuperior meatal wall) had the highest baring of $63 \%(n=7)$, followed by retroauricular fistula $27 \%(n=3)$, Bezold's abscess $9 \%(n=1)$.

It is of note that the lesions of middle-ear mucosa followed the frequency internal distribution law. By internal, it is meant that the structure of the distribution is identical to the

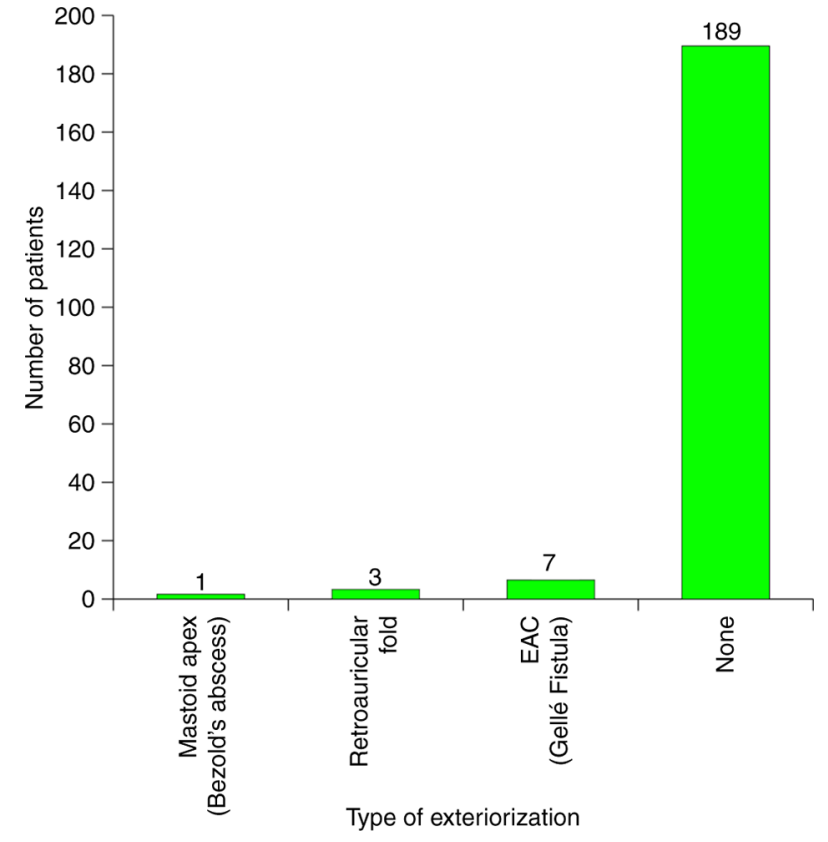

Figure 8. Absolute frequencies of the exteriorization of suppurative process. EAC, external acoustic canal.

topographic structure of middle-ear cavities. If these cavities are considered as a co-axial suite, it could be observed that the structure of absolute frequencies acted similarly to a non-linear orderly series with an inflexion corresponding to the barrier between the anterior and posterior half of the tympanic cavity (Fig. 9).

Distribution of patients according to the type and rank of surgery is presented in Fig. 10. The rank of surgery became significant when it was considered that the main study comparison criteria was time.

Fig. 11 presents the distribution of patients according to type of disease and type of tympanic membrane (TM) 


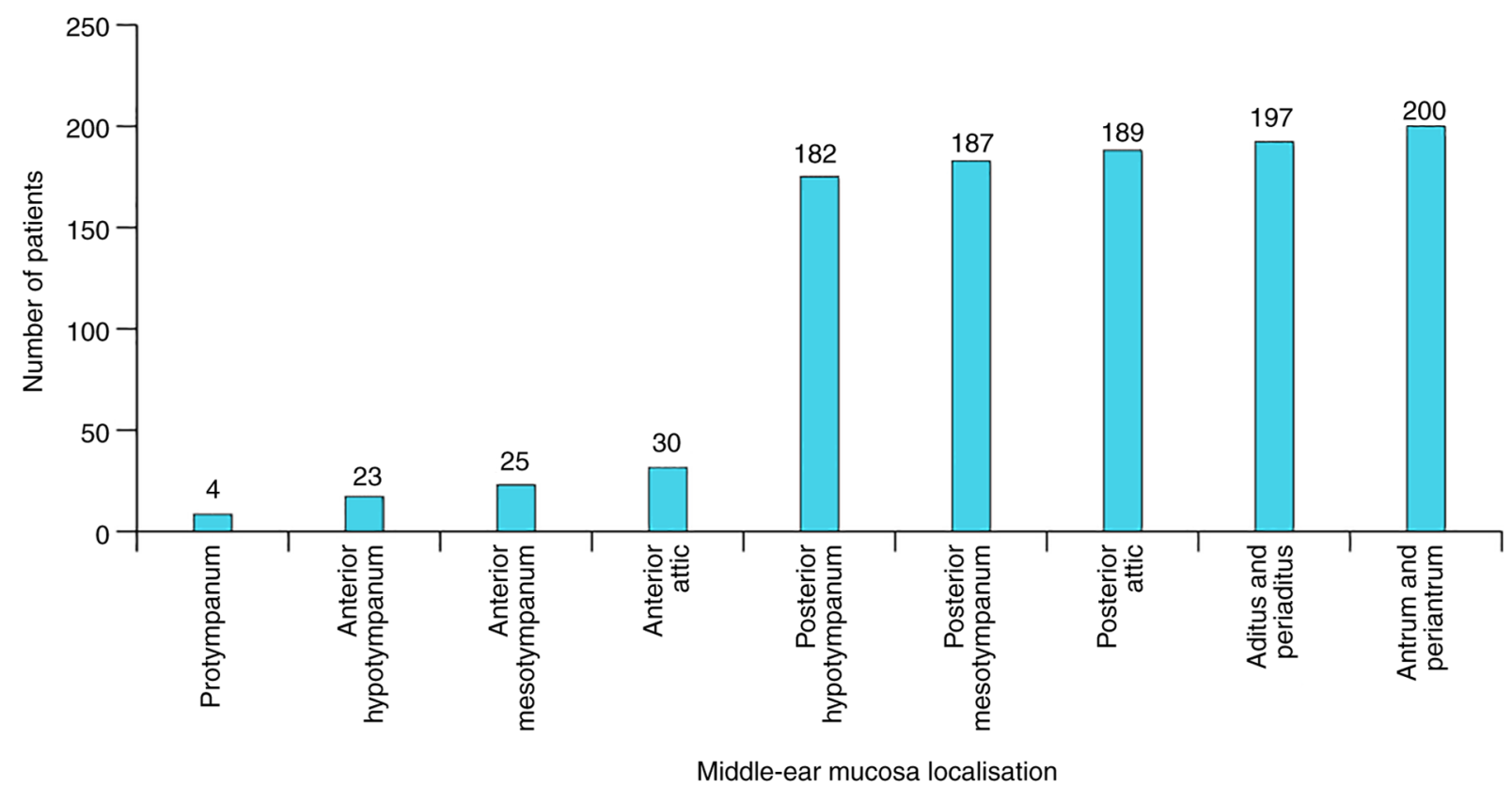

Figure 9. Absolute frequencies of middle-ear mucosa lesion localization.

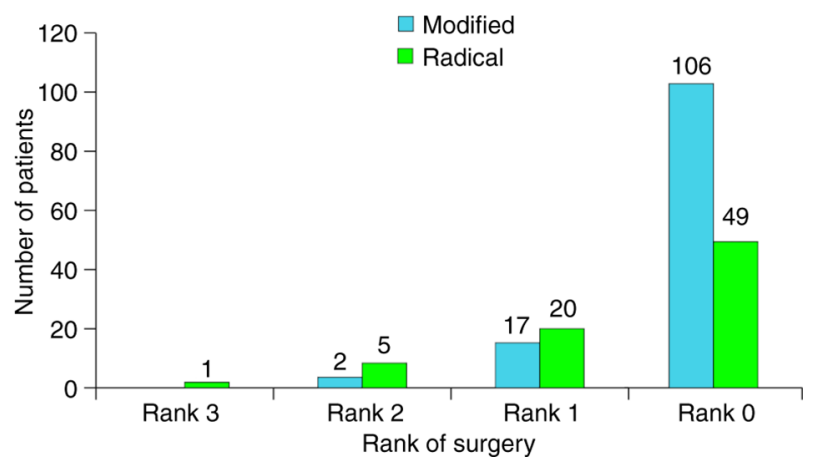

Figure 10. Patient distribution according to the rank of surgery. Rank 0, first surgery; rank 1, first reintervention; rank 2, second reintervention; rank 3 , third reintervention.

perforation. The relative frequency of marginal perforation was $37.5 \%$ and that of cholesteatoma $28 \%$. Fig. 12 shows the frequency distribution of marginal perforations with the highest frequency for posterosuperior quadrant and posterior part of Shrapnell's membrane and the lowest for anterosuperior localization. Fig. 13 addresses non-marginal perforations with the highest frequency for subtotal perforations. The specific weights of posterior localization for both types of perforations were as follows: $76 \%$ for marginal and $88 \%$ for non-marginal. Fig. 14 represents an explanation for the localization codes from Figs. 12 and 13. The letter ' $m$ ' stands for marginal perforation, whilst 'non' stands for non-marginal. The numbers refer to the area covered by the perforation and define the specific quadrants of the pars tensa of the TM as well as the halves of the pars flaccida (Shrapnell's membrane). As depicted, some large perforations cover several neighbouring areas.

The state of the OC, as documented intra-op is presented in Fig. 15. The specific behaviour for each component of the OC in rapport to the inflammatory status of the adjacent area was noted. Thus, the stapes reacts by partial lysis and fixation

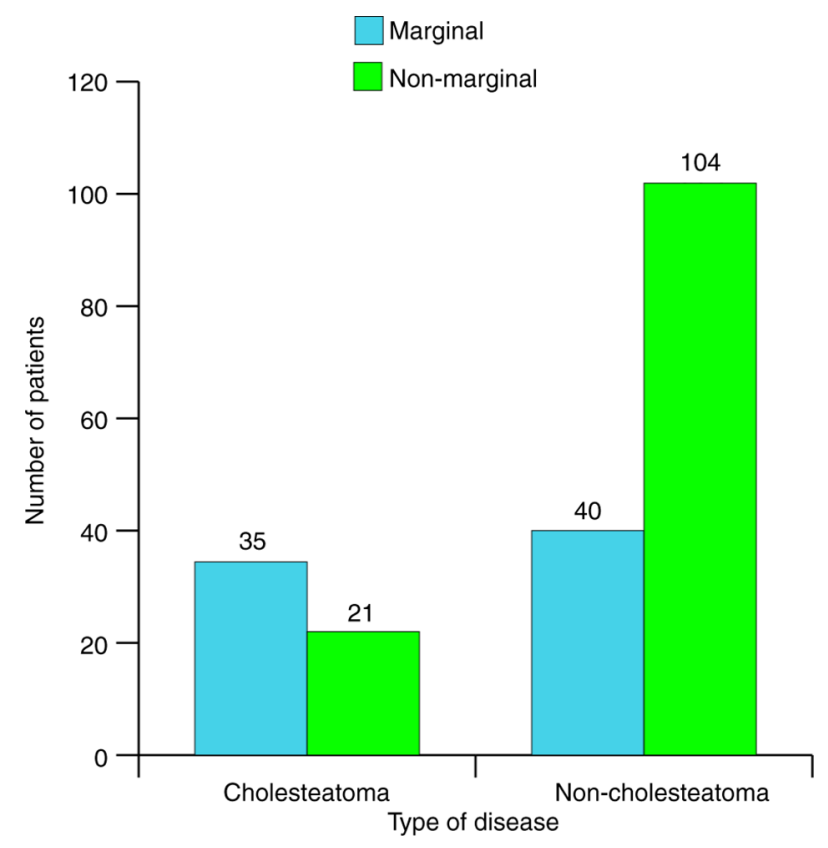

Figure 11. Patient distribution according to the type of disease and type of tympanic membrane perforation.

to the oval window, the malleus by total lysis, whilst the incus by osteolysis. The most resistant towards total osteolysis was the stapes, followed by the malleus. The incus was the most susceptible to this process. This type of differentiated behaviour means that the total absence of the OC (including stapes footplate) is relatively rare (7\%), fixation of a complete OC in almost double the cases (13\%), preserved complete and mobile OC in $14 \%$ and interrupted OC with the highest frequency of $68 \%$. This last situation represents the characteristic response of the OC to chronic inflammatory disease of the middle-ear (Figs. 16-20). 


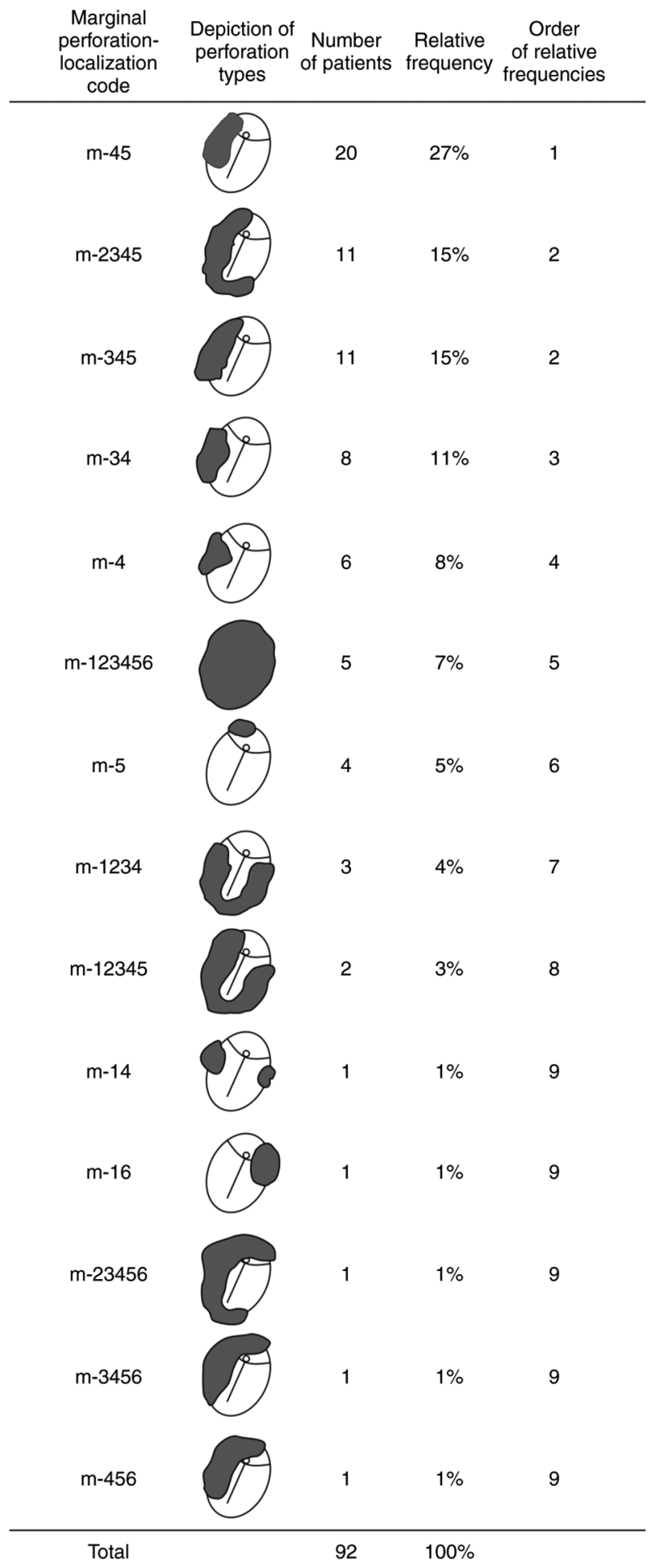

Figure 12. Absolute and relative frequencies of marginal tympanic membrane perforations.

As far as success goes, the objective of the surgery is to drain the inflammatory process and to create a new self-cleaning external ear, a cavity with uniform walls that does not allow cerumen deposits to form. Fig. 21 shows the global drainage results of mastoidectomy in absolute frequencies with a success rate of $77.5 \%$. Since completely self-cleaning ears are rather rare even in healthy individuals, this objective was considered to be optional. It would however instore quality of life (QoL) in the sense that the patient could become independent from

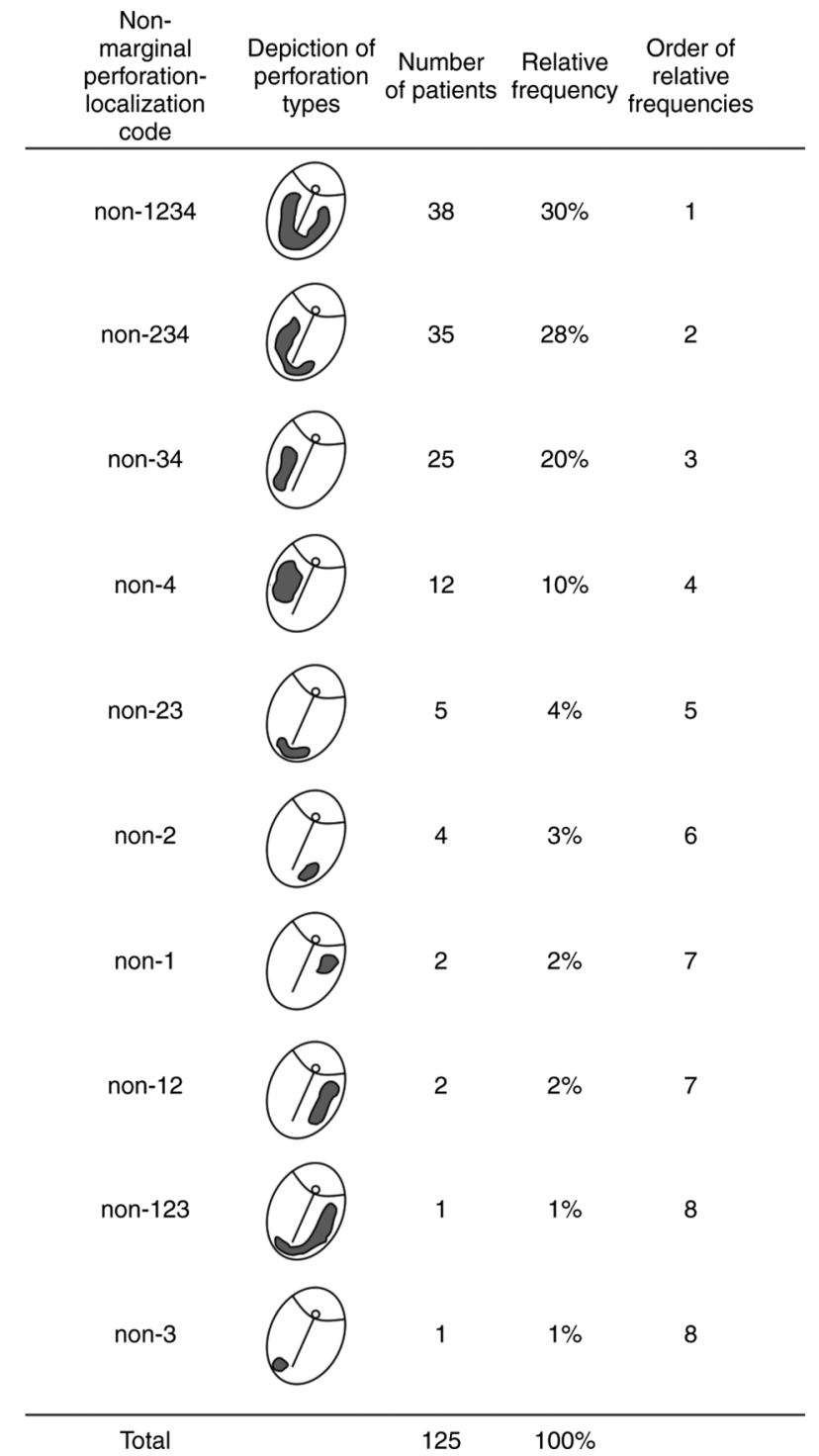

Figure 13. Absolute and relative frequencies of non-marginal tympanic membrane perforations.

periodic visits to clinical settings for cerumen removal. If the functional status of the ear is also satisfactory it would bring total independence for the patient, which is the purpose of surgery. Paradoxically, self-cleaning was present in $11 \%$ of mastoidectomy failures (Fig. 22) where it would be expected to be completely absent. In the successful cases, there was an $86 \%$ self-cleaning rate, which was lower than expected. Overall, the global rate was $70 \%$, which is probably the limit of our future expectations on the subject. It can therefore be stated that self-cleansing of a cavity is an intrinsic property of the cavity and is governed by unclear internal laws, such as normal keratosis and type of desquamation.

Failure of drainage requires further discussion since it was defined by the appearance of one otorrhea episode in 7.86 years (one every 94 months), but the appearance of 36 episodes (one every 3 months) also represented failure. In principle, both situations are failures, but the specific situation is different for each case, especially from the patient's point of view. This meant that we had to find a way to differentiate failure and for this purpose an arbitrary scale was created to 


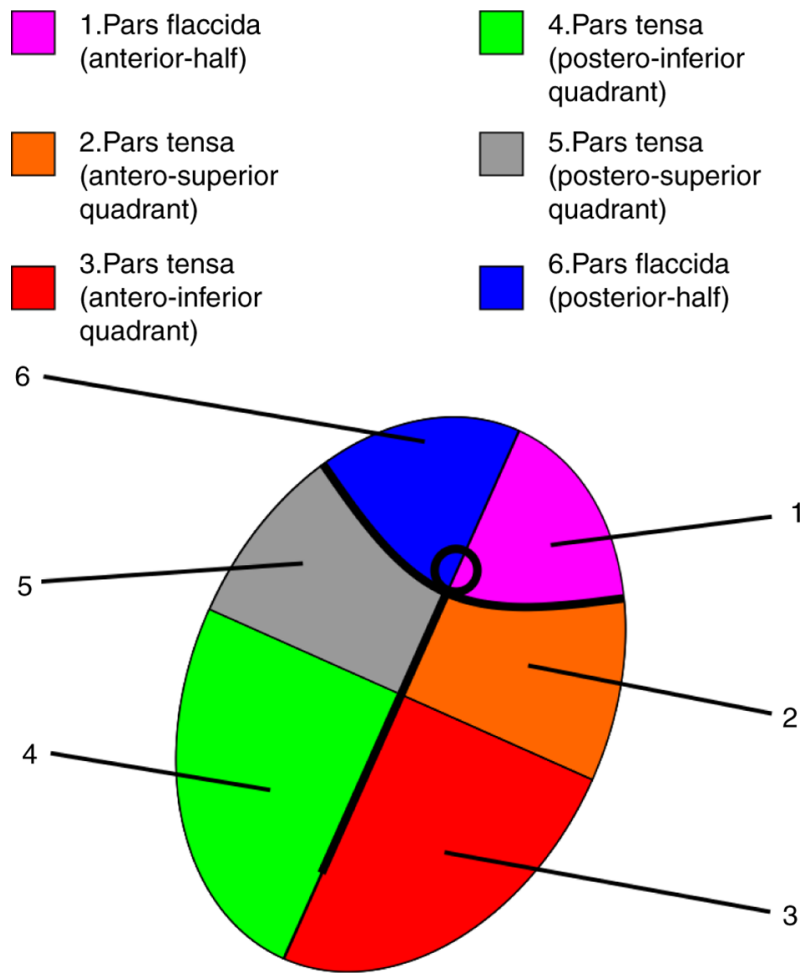

Figure 14. Topography of tympanic membrane regions explaining the types of perforations described.

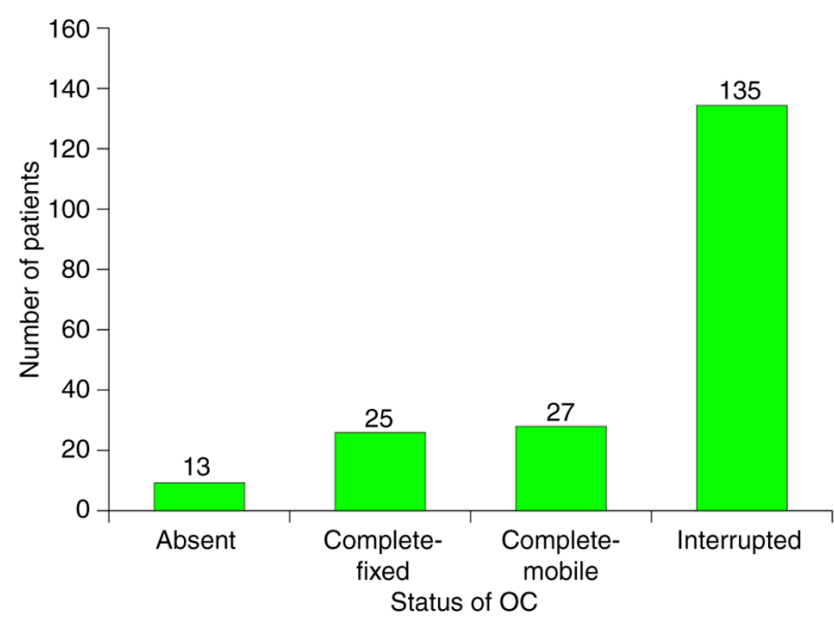

Figure 15. Patient distribution according to the status of the OC. OC, ossicular chain.

quantify comfort/discomfort of patient related to the number of otorrhea episodes. Maximum discomfort (100\% drainage failure) was considered as monthly otorrhea episodes for the entire 7.86 years (94 months $=94$ episodes). This meant that the most notable failure, 36 episodes in 7.86 years (one episode every 3 months) corresponded to a $38 \%$ discomfort rate and the smallest failure of two episodes in 7.86 years (one every 48 months) to a $2 \%$ discomfort rate. Fig. 23 shows the success of drainage corresponding to each comfort/discomfort group in absolute frequencies. Out of 45 patients with drainage failure two had the highest discomfort score of $38 \%$ and most of them $(n=15)$ had the lowest score of $2 \%$. Fig. 24 presents the same

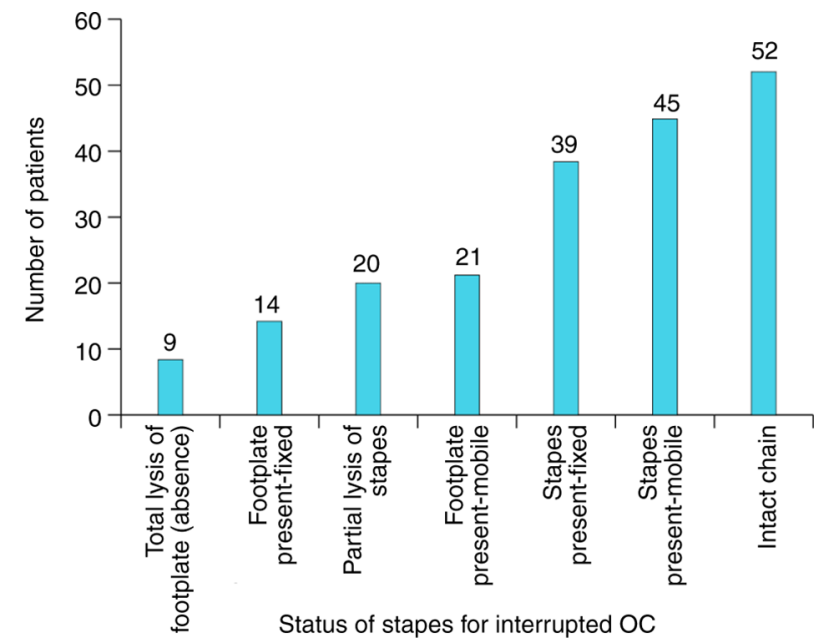

Figure 16. Patient distribution according to the status of stapes with interrupted OC. OC, ossicular chain.

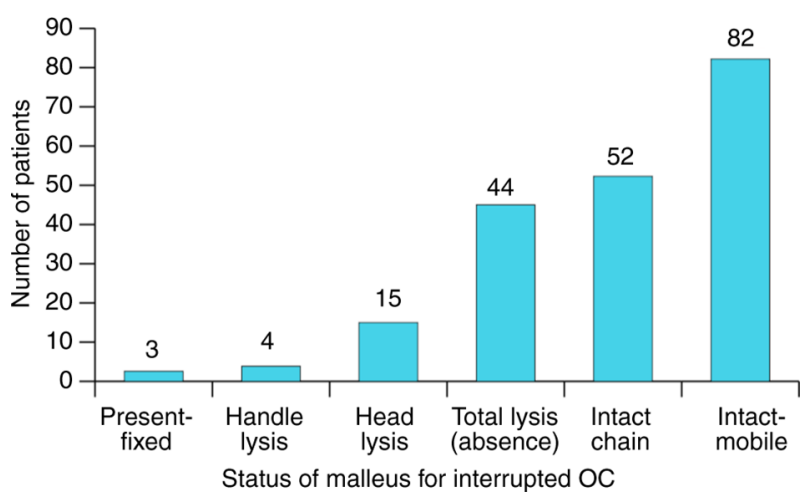

Figure 17. Patient distribution according to the status of malleus with interrupted OC. OC, ossicular chain.

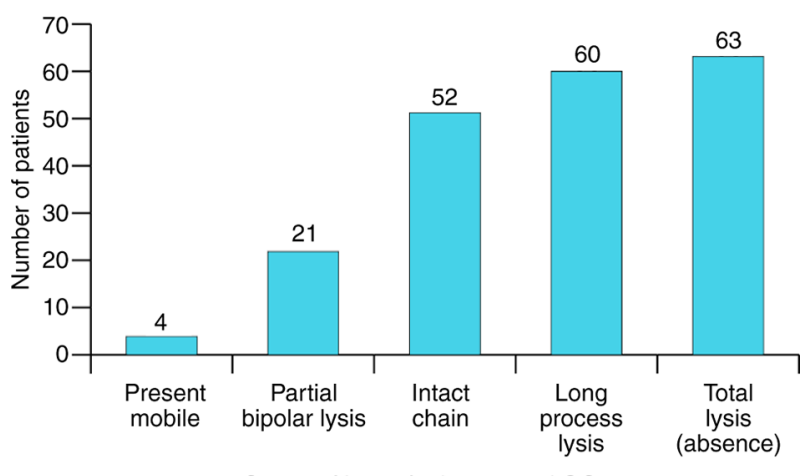

Figure 18. Patient distribution according to the status of incus with interrupted OC. OC, ossicular chain.

scores for failure patients; it was found that $81 \%$ of them had a discomfort score of up to $10 \%$.

Although in our previous articles concerning functional results of mastoidectomy for the same cohort of patients $(11,12)$, we encountered several factors that influenced results, in the present study only three seemed to have the expected influence on drainage results, including type of disease, type of 


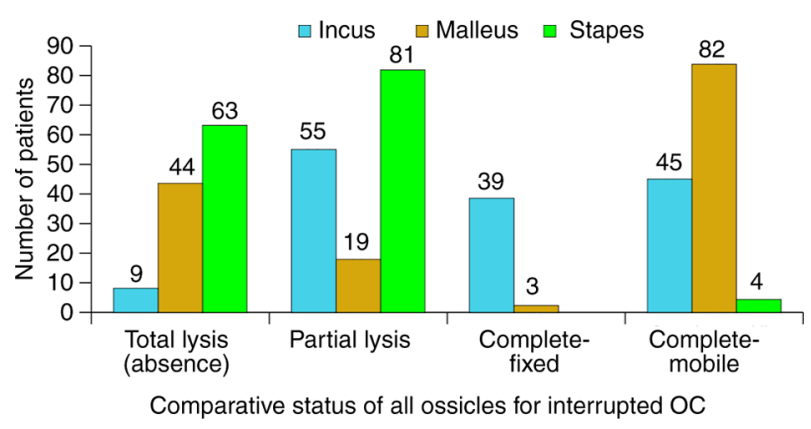

Figure 19. Comparative status of all ossicles for interrupted OC. OC, ossicular chain.

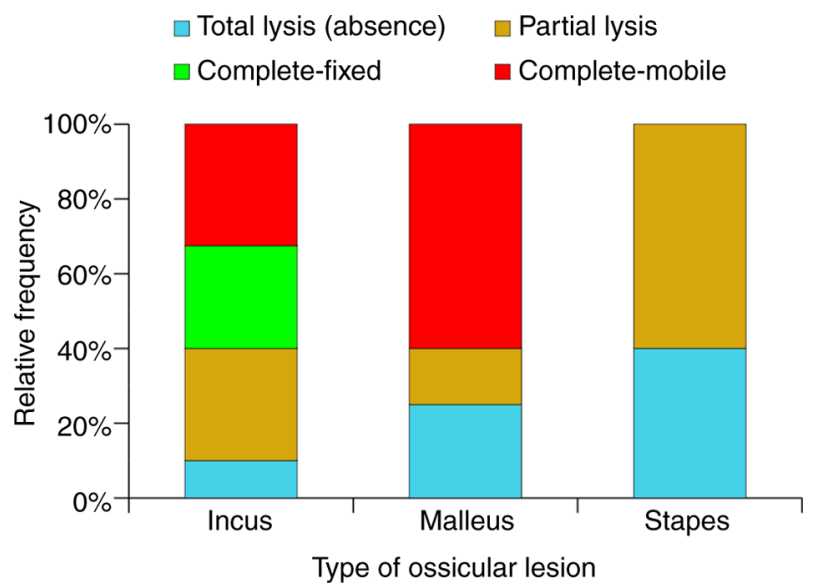

Figure 20. Relative frequency of ossicular lesions for interrupted ossicular chain.

perforation and type of surgery. Presence of cholesteatoma increased the rate of drainage success by $11 \%$, marginal perforation by $7 \%$ and MRM by $4 \%$ (Figs. 25-27). By comparing the global rates of success and/or failure to variables proven to modify as expected the said rates, an influence of maximum $8 \%$ of cholesteatoma presence was defined. Statistically the value was significant, but a definitive conclusion cannot be stated in the present study. Some of the variables, such as presence of complications, clinical stage and total lesion score, yielded paradoxical results and did not allow us to draw an applicable conclusion concerning the involvement of these factors in the evolution of long-term drainage results (Figs. 28-30).

The most useful conclusion came from the distribution of middle-ear mucosa lesions (Fig. 9). If the series of data are concatenated from the chart, we obtain $10 \%$ for lesions localized anterior and $90 \%$ posterior to a frontal conventionally drawn geometric plan running through the middle of the tympanic cavity, dividing the axial and coaxial spaces of the ME (by ME we understand the sum of protympanum and the cells around it, tympanic cavity with corresponding cells, aditus and antrum with peri-adital cells, mastoid antrum with peri-antral cells) into two segments-anterior and posterior to the defined geometric plan. The concatenation involved calculating the mean value and adjusting it to $100 \%$ of the newly obtained structure. By comparing these empirical series to the theoretic series of endo-temporal cavity distribution with

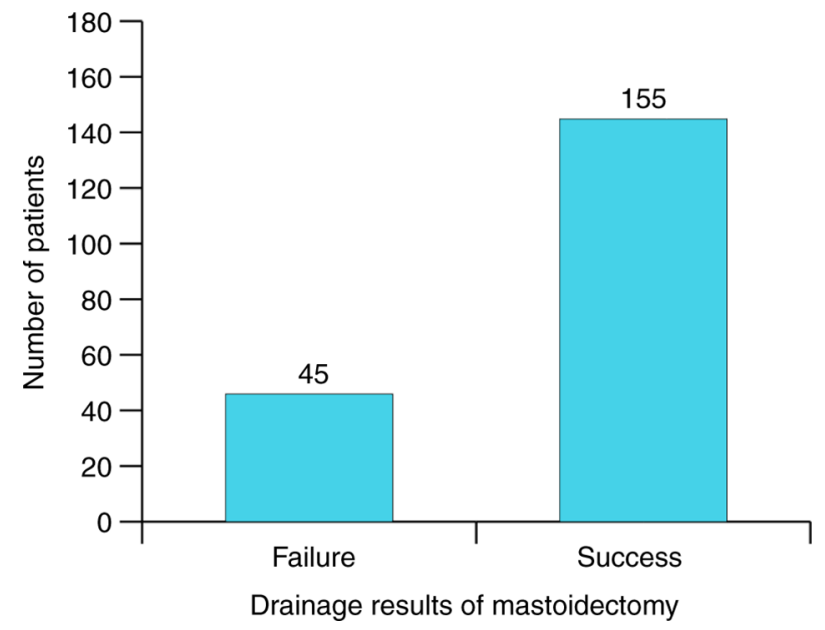

Figure 21. Global drainage results of radical mastoidectomy.

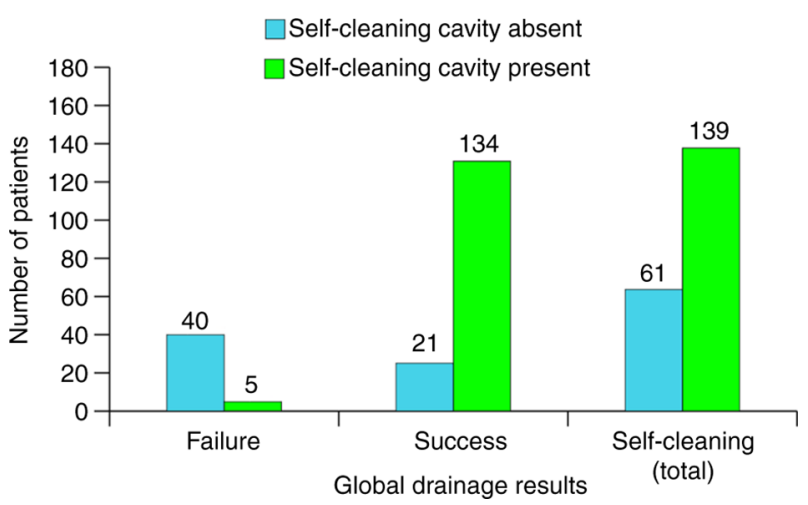

Figure 22. Patient distribution according to global drainage results.

variable geometry of the ME similar structures were obtained: i) Peri-protympanum, $7 \%$; ii) peri-tympanic cavity, $18 \%$; iii) peri-aditus, $10 \%$; and iv) peri-antrum, $65 \%$.

Considering this series, in accordance with the geometrical plane defined above, the following distribution was obtained: i) Peri-protympanum, 7\%; ii) peri-tympanic cavity-anterior of plane, $9 \%$; conventional frontal plane; iii) peri-tympanic cavity-posterior of plane, $9 \%$; iv) peri-aditus, $10 \%$; and v) peri-antrum, $65 \%$.

This in turn led to the new theoretical series: i) Protympanum 7\%; ii) peri-tympanic cavity-anterior of plane, $9=16 \%$; conventional frontal plane; iii) peri-tympanic cavity-posterior of plane $9 \%+$ peri-aditus $10 \%+$ peri-antrum $65=84 \%$.

The empirical series in turn (Fig. 9) became: periprotympanum + peri-tympanic cavity $=10 \%$; conventional frontal plane; peri-tympanic cavity-posterior of plane + peri-aditus + peri-antrum $=90 \%$.

The two series (theoretical and experimental) obviously had similar structures. They were compared with the drainage results of $78 \%$ success and $22 \%$ failure. To do so it was stated that, theoretically, radical mastoidectomy completely cleaned the peri-antrum cells (65\% of total), almost all of the peri-aditus cells (10\% of total), less than half of the peri-tympanic cavity cells $(18 \%)$ and none of the peri-protympanum cells $(7 \%)$. Practically the surgery cleaned much less than 


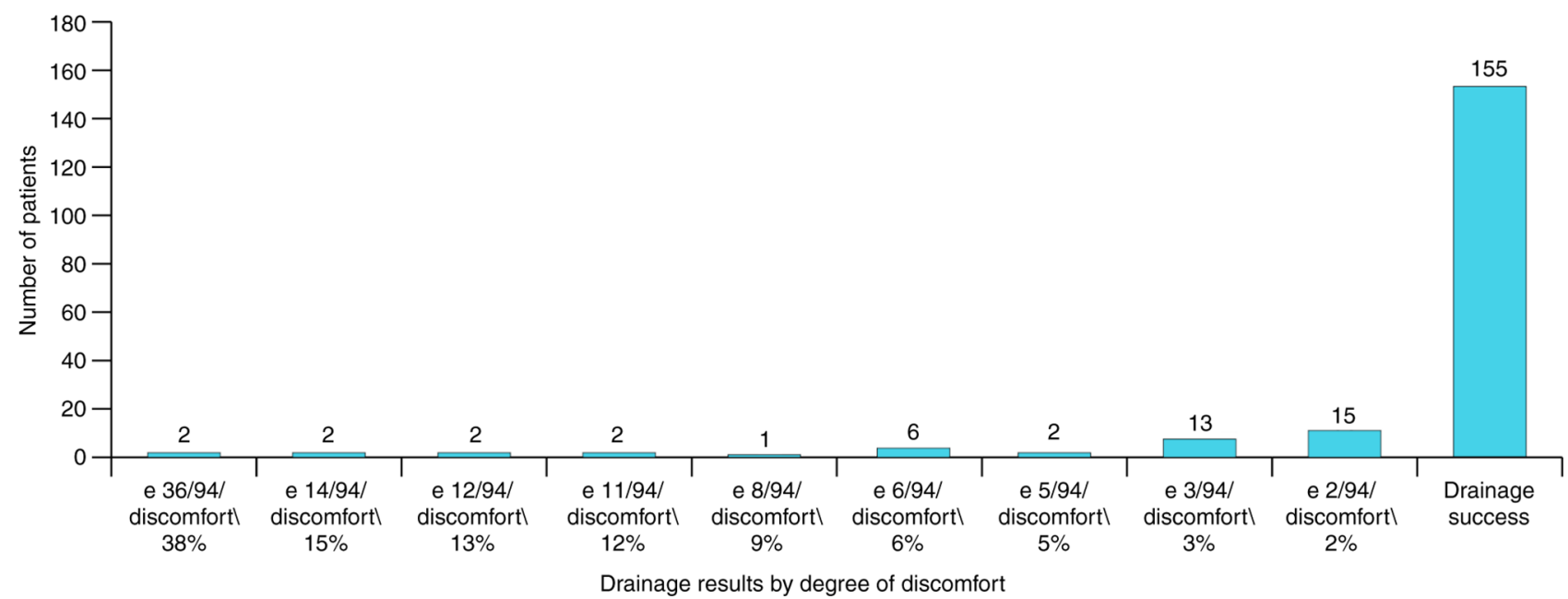

Figure 23. Patient distribution according to degree of discomfort.

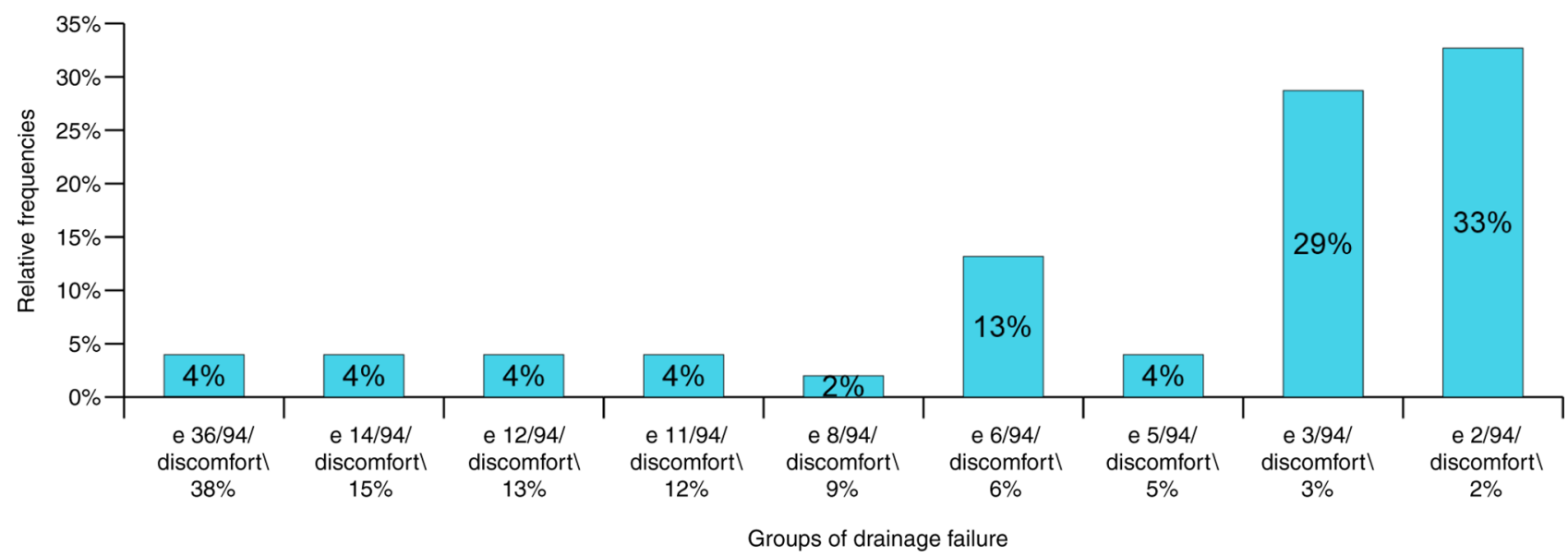

Figure 24. Relative frequencies of drainage failure.

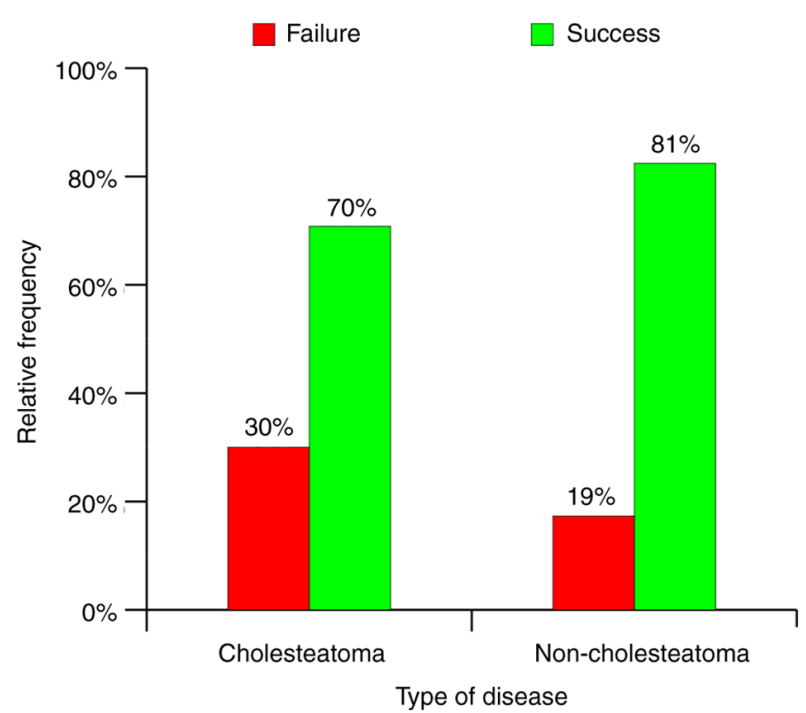

Figure 25. Influence of the type of disease on drainage results.

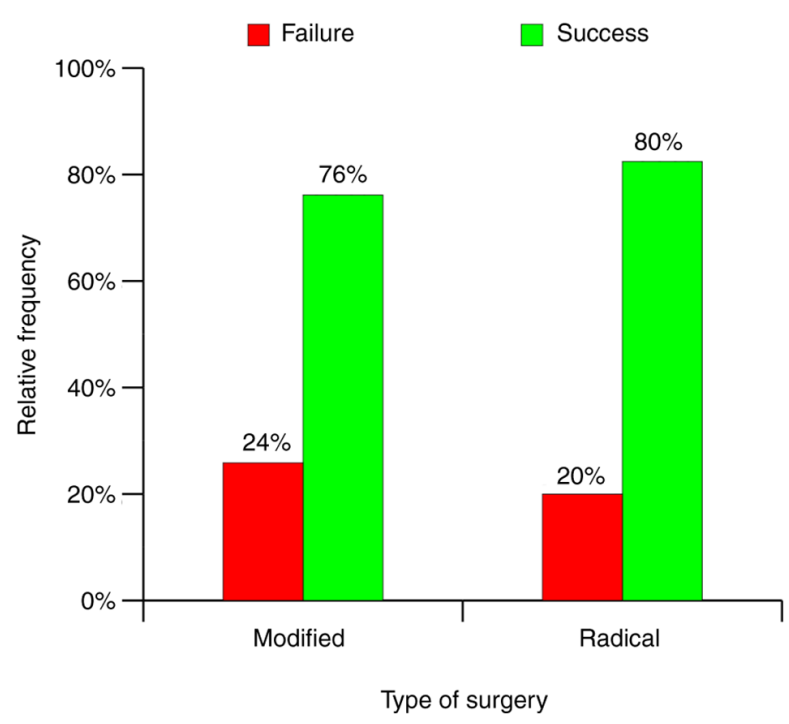

Figure 26. Influence of the type of surgery on drainage results.

the theoretically predicted ratio: Peri-antrum $=0.65 \mathrm{x}(\mathrm{x} \rightarrow 1), \quad$ and peri-protympanum $=0.07 \mathrm{w}(\mathrm{w} \rightarrow 0)$. The maximum peri-aditus $=0.1 \mathrm{y}(\mathrm{y} \rightarrow 1)$, peri-tympanic cavity $=0.18 \mathrm{z}(\mathrm{z} \rightarrow 0.5) \quad$ obtainable value for the sum $0.65 \mathrm{x}+0.1 \mathrm{y}+0.18 \mathrm{z}+0.07 \mathrm{w}$ 


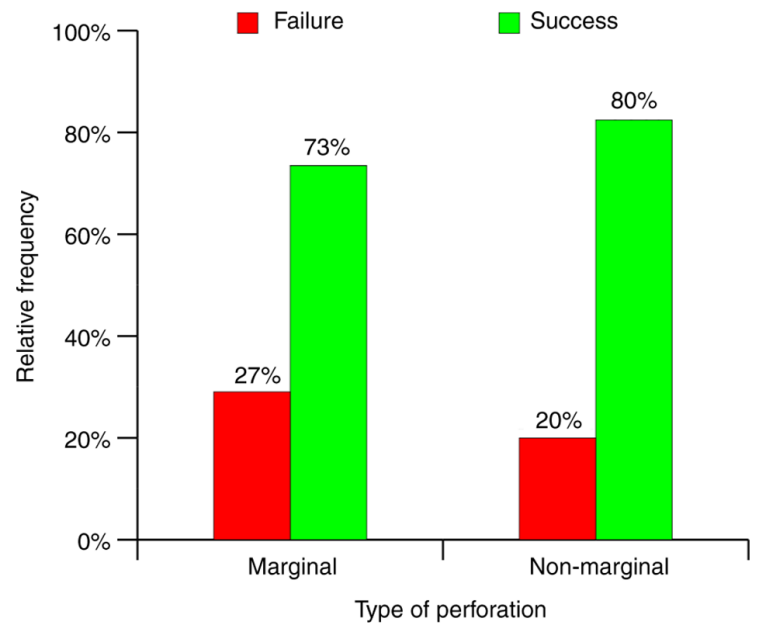

Figure 27. Influence of the type of TM perforation on drainage results.

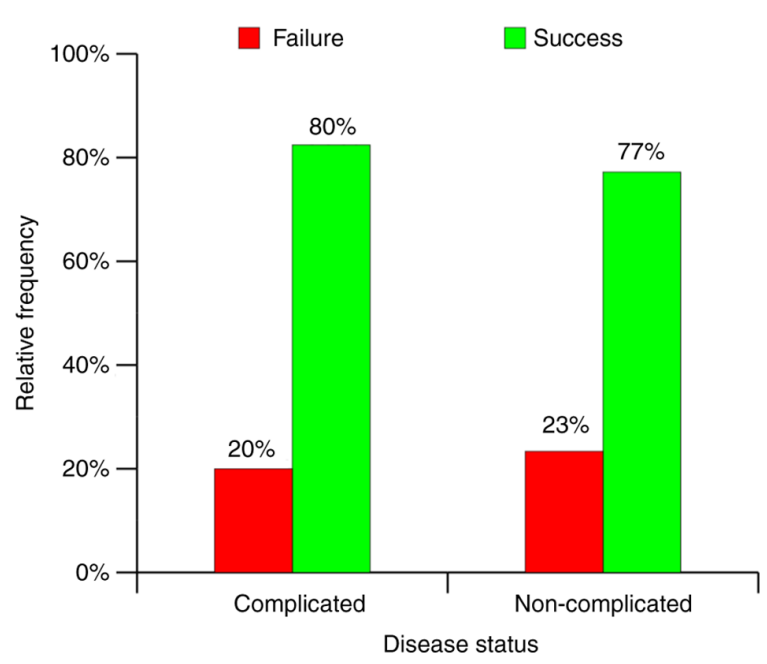

Figure 28. Influence of the disease status on drainage results.

was $84 \%$. This meant that practically and ideally, a maximum of $84 \%$ could be cleaned out of the mastoid and petrous cells. The remaining $16 \%$ may contain irreversible lesions. The results of almost $78 \%$ were congruent to this theory.

From a practical point of view, no surgeon should expect to drain the entire endo-temporal structure since this type of exercise is rarely realized in experiments or dissections. This means that we must admit that some of the pneumatic cavities cannot be surgically approached, dividing the mastoid bone into surgical cavities and non-surgical cavities. The rate of success of mastoidectomy is entirely dependent on the chance that all lesions will be in a surgical area and this chance is a function of the proportion of pneumatic cells for each of the mentioned areas. Simplifying the process, it was stated in the present study that the proportion of surgical cavities was $75 \%$ (antrum, aditus and adjacent cells) and non-surgical cavities was $25 \%$ (tympanic cavity, protympanum and adjacent cells). Failure should, in turn, be discussed as medical research can occasionally require a high degree of abstraction (13) and failure itself is not an unequivocal clinical fact and it requires divisions and nuances as we have previously stated (Figs. 23 and 24). The cause of failure is obvious whilst the cause of its division is the normal law of probability distribution that guides the division of remnant lesions in the non-surgical cells. In other words, the more remnant lesions in non-surgical cells, the higher the failure rate and intensity (higher number of otorrhea episodes, lower patient comfort).

In comparison, Mukherjee et al (2) proposed a study on 133 patients with MRM and published long-term functional and anatomical results. Their criteria included the notion of waterproof ears (no otorrhea after exposure to water) and the study reported $95 \%(n=126)$ as such $(2)$. The anatomical status of the stapes and the degree of ventilation within the middle-ear are also considered proof of a successful operation, in accordance with the conclusions of the present study and those of other authors $(5,14)$. Comparing results of different studies is however complicated by case-mix variation as some centres may have a larger number of complicated cases with higher probability for poor post-operative results (2). These concerns can be addressed by using scores such as the SPITE score described by Black (15) (points for various factors, such as presence of infection and previous surgery) or our own previously presented complication score (7) (Tables I and II).

A smaller study by Lucidi et al (16) published the results of 31 patients with both CWU and CWD mastoidectomies and followed the QoL over an average of 12 months post-op. They concluded that after 12 months, epithelization is complete, and the patient can provide reliable self-assessment concerning QoL. However, the authors noted that such a short follow-up may not be sufficient to consider these results as conclusive. The recurrence rate for $\mathrm{CWU}$ was $20-30 \%$ and $5-9 \%$ for CWD, in accordance with the conclusions of the present study and those of other published studies $(16,17)$.

A more extensive study by Kos et al (1) analysed 259 cases for both functional and anatomical results for a period of 1 to 24 years (mean period of 7 years, very similar to the present study). Recurring infections of the cavity were reported in $11.9 \%(n=31)$ of cases within 6 years post-op and in $6.5 \%(n=17)$ of cases $>6$ years post-op. Overall, a dry and self-cleaning cavity was obtained in $95 \%$ of cases. Complications included polyps, recurrent cholesteatoma, TM perforation and meatal stenosis (1). These results were considered congruent with those reported by a significant number of other researchers (18-21). In comparison, a study by Kuo et al (22) reported a total of $4.9 \%$ ear discharge with residual cholesteatoma mainly affecting the attic and retrotympanum, which was similar to other previously published studies (22-24). Nadol (25) defined the sigmoid sinus and tegmen air cells as the most common recurrence site, while Veldman and Braunius (20) considered the facial nerve and sigmoid sinus as most frequent (20). A previous study by Prasanna Kumar et al (26) defined the mastoid cells as the most common recurrence site, followed by sinodural angle, sinus tympani and tegmen antri region.

A similar study was performed by Pareschi et al (27) reported long-term anatomical and functional results (10 years follow-up) for a total of 895 patients with a total recidivism rate of $7.7 \%(n=69)$, of which $6.7 \%(n=60)$ showed persistence of disease and $1 \%(n=9)$ showed recurrence. Of the 60 cases, the largest rate of persistence was in the posterior mesotympanum $(n=52)$, followed by the anterior mesotympanum $(n=5)$ and hypotympanum $(\mathrm{n}=3)$, which validates our previously 
Failure

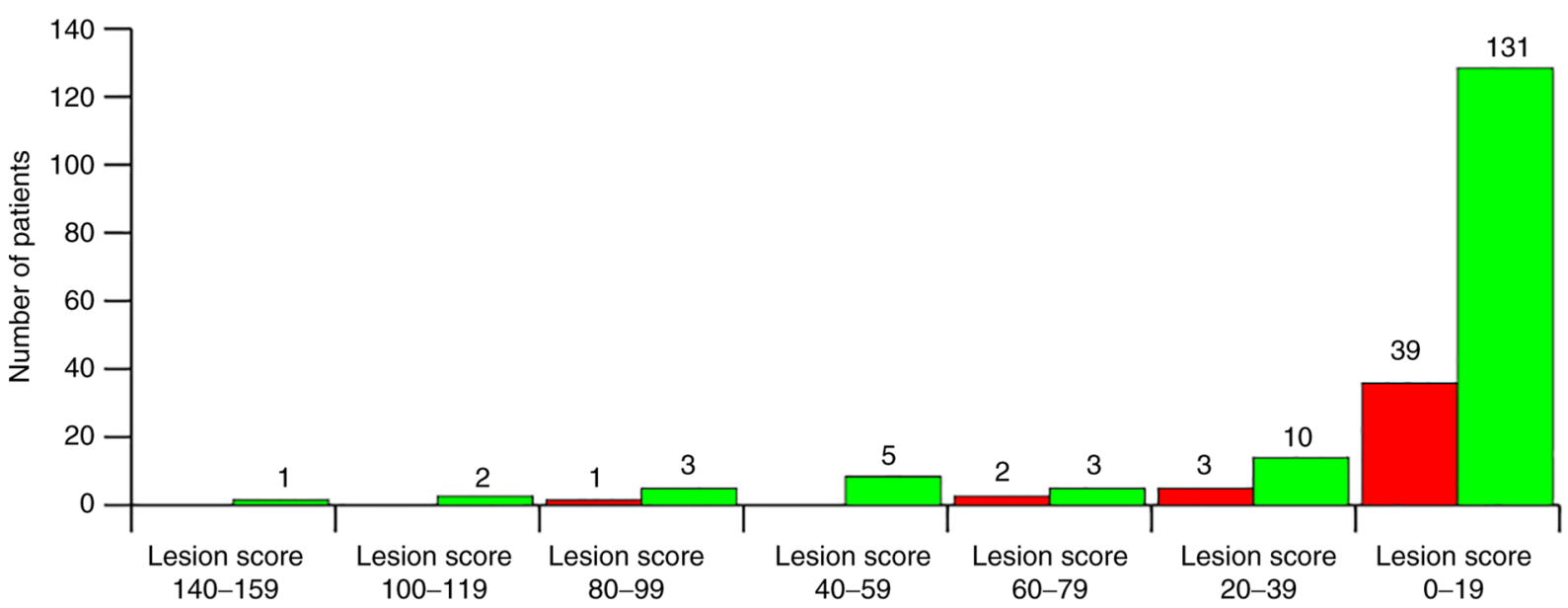

Groups of total lesion score (absolute frequencies)

Figure 29. Absolute frequencies of total lesion scores distribution.

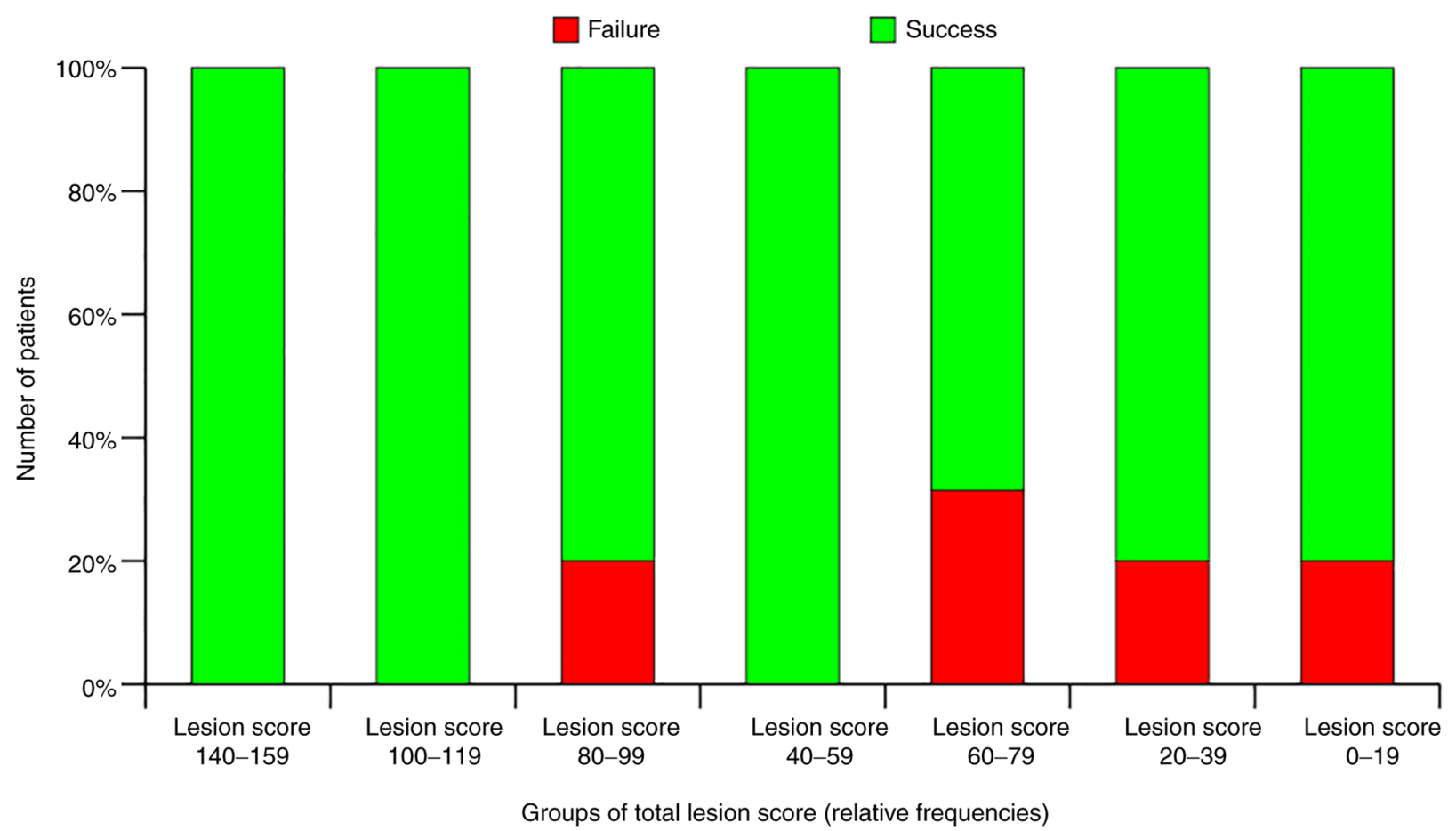

Figure 30. Relative frequencies of total lesion scores distribution.

stated conclusions on lesion distribution (7). Pareschi et al (27) and Vartiainen (28) also stated that prognostic factors for recidivism include the status of the TM and middle-ear mucosa, age of the patient and length of follow-up, since cholesteatoma recurrence can develop even after 12 years, thus confirming the conclusions of the present study.

Blanco et al (29) also reported on 45 cases of CWD surgery with a success rate of 93.3 and $6.6 \%$ recurrence, which was less than other similar studies such as Lin and Oghala (30). The main limitation of the previous study by Blaco et al was the short follow-up period of only 28 months (29).

To conclude, successful mastoidectomy was defined in the current study as the total absence of otorrhea episodes after total epithelization of cavity and failure of the presence of at least one such episode. A successful drainage (anatomical results) ensured long-term stability of hearing (functional results). The two types of results of mastoidectomy were expressions of the same phenomenon defined as a conversion of a static population by binary division in respect to the spatial distribution of its constituting units. Drainage results were found to be linked by an analytical function to factors with clinical predictive significance, such as complications of disease, exteriorization of suppurative disease, lesions of the ME mucosa and TM, rank of surgery, status of the OC, age of patient and length of follow-up. The global drainage success rate was $77.5 \%$, and the best self-cleaning rate was 
$86 \%$ with a global self-cleaning rate of $70 \%$. From a practical point of view, no surgeon should expect to drain the entire endo-temporal structure since this type of exercise is rarely realized in experiments or dissections. This means that we must admit that some of the pneumatic cavities cannot be surgically approached, dividing the mastoid bone into surgical cavities and non-surgical cavities. Practically and ideally, we can clean out a maximum of $84 \%$ of the mastoid and petrous cells. Our results of almost $78 \%$ are congruent to this theory. The remaining $16 \%$ may contain irreversible lesions. The rate of success of mastoidectomy is entirely dependent on the chance that all lesions be in a surgical area and this chance is a function of the proportion of pneumatic cells for each of the mentioned areas. Most of the non-surgical cavities are located in the tympanic cavity, protympanum and adjacent cells. The more remnant lesions in non-surgical cells, the higher the failure rate and intensity (higher number of otorrhea episodes, lower patient comfort).

\section{Acknowledgements}

Not applicable.

\section{Funding}

No funding was received.

\section{Availability of data and materials}

All data generated or analyzed during this study are included in this published article.

\section{Authors' contributions}

HM and MR contributed equally to this work and should, therefore, both be considered first authors of this article. HM and MR were responsible for the original idea, conception, patient selection and care, operations, data collection and editing structure. AIM, GC AB and MAS made substantial contributions to acquisition, analysis and interpretation of data and gave a final view of the article. MAS was also responsible for the data analysis and graphical representation of the results. All authors have read and approved the final manuscript. HM and MR confirm the authenticity of all the raw data.

\section{Ethics approval and consent to participate}

For this study, ethical approval was obtained from the Research Ethics Committee of the Faculty of Medicine, Titu Maiorescu University (approval no. 1/25.05.2021; Bucharest, Romania). All patients provided informed written consent.

\section{Patient consent for publication}

Not applicable.

\section{Competing interests}

The authors declare that they have no competing interests.

\section{References}

1. Kos MI, Castrillon R, Montandon P and Guyot JP: Anatomic and functional long-term results of canal wall-down mastoidectomy. Ann Otol Rhinol Laryngol 113: 872-826, 2004.

2. Mukherjee P, Sauders N, Liu R and Fagan P: Long-term outcome of modified radical mastoidectomy. J Laryngol Otol 118: 612-616, 2004.

3. Lv J, Li H, Wu X, Chen X and Huang Y: Functional results of revision canal wall down mastoidectomy. J Bio-X Res 2: 98-103, 2019.

4. Nyrop M and Bonding P: Extensive cholesteatoma: Long-term results of three surgical techniques. J Laryngol Otol 111: 521-526, 1997.

5. Cook J, Krishnan S and Fagan PA: Hearing results following modified radical versus canal-up mastoidectomy. Ann Otol Rhinol Laryngol 105: 379-383, 1996.

6. Mocanu H, Mocanu AI, Drăgoi AM and Rădulescu M: Long-term histological results of ossicular chain reconstruction using bioceramic implants. Exp Ther Med 21: 260, 2021.

7. Mocanu H, Mocanu AI, Bonciu A, Coadă G, Schipor MA and Rădulescu M: Analysis of long-term functional results of radical mastoidectomy. Exp Ther Med 22: 1216, 2021.

8. Neudert M, Bornitz M, Mocanu H, Lasurashvili N, Beleites T, Offergeld $\mathrm{C}$ and Zahnert T: Feasibility study of a mechanical real-time feedback system for optimizing the sound transfer in the reconstructed middle ear. Otol Neurotol 39: e907-e920, 2018.

9. Mocanu H, Bornitz M, Lasurashvili N and Zahnert T: Evaluation of Vibrant ${ }^{\circledR}$ Soundbridge ${ }^{\mathrm{TM}}$ positioning and results with laser Doppler vibrometry and the finite element model. Exp Ther Med 21: 262, 2021

10. Neagu A, Mocanu AI, Bonciu A, Coadă G and Mocanu H: Prevalence of GJB2 gene mutations correlated to presence of clinical and environmental risk factors in the etiology of congenital sensorineural hearing loss of the Romanian population. Exp Ther Med 21: 612, 2021

11. Fagan PA: Modified radical mastoid surgery for chronic ear disease. Ann Acad Med Singap 20: 665-673, 1991.

12. Perez de Tagle JR, Fenton JE and Fagan PA: Mastoid surgery in the only hearing ear. Laryngoscope 106: 67-70, 1996.

13. Alecu I, Mocanu H and Călin IE: Intellectual mobility in higher education system. Rom J Mil Med 120: 16-21, 2017.

14. Fisch U and Schmid S: Radical mastoido-epitympanectomy with tympanoplasty and partial obliteration: A new surgical procedure? Ann Acad Med Singap 20: 614-617, 1991.

15. Black B: Prevention of recurrent cholesteatoma: Use of hydroxyapatite plates and composite grafts. Am J Otol 13: 273-278, 1992.

16. Lucidi D, de Corso E, Paludetti G and Sergi B: Quality of life and functional results in canal wall down vs canal wall up mastoidectomy. Acta Otorhinolaryngol Ital 39: 53-60, 2019.

17. Kerckhoffs KG, Kommer MB, van Strien TH, Visscher SJ, Bruijnzeel H, Smit A and Grolman W: The disease recurrence rate after the canal wall up or canal wall down technique in adults. Laryngoscope 126: 980-987, 2016.

18. Austin OF: Staging in cholesteatoma surgery. J Laryngol Otol 103: 143-148, 1989

19. Parisier SC, Hanson MB, Han JC, Cohen AJ and Selkin BA: Pediatric cholesteatoma: An individualized, single-stage approach. Otolaryngol Head Neck Surg 115: 107-114, 1996.

20. Veldman JE and Braunius WW: Revision surgery for chronic otitis media: A learning experience. Report on 389 cases with a long-term follow-up. Ann Otol Rhinol Laryngol 107: 486-491, 1998.

21. Lau T and Tos M: Treatment of sinus cholesteatoma. Long-term results and recurrence rate. Arch Otolaryngol Head Neck Surg 114: 1428-1434, 1988.

22. Kuo CY, Huang BR, Chen HC, Shih CP, Chang WK, Tsai YL, Lin YY, Tsai WC and Wang CH: Surgical results of retrograde mastoidectomy with primary reconstruction of the ear canal and mastoid cavity. Biomed Res Int 2015: 517035, 2015.

23. Gaillardin L, Lescanne E, Moriniere S, Cottier JP and Robier A: Residual cholesteatoma: Prevalence and location. Follow-up strategy in adults. Eur Ann Otorhinolaryngol Head Neck Dis 129: 136-140, 2012.

24. Haginomori AI, Takamaki A, Nonaka R and Takenaka H: Residual cholesteatoma: Incidence and localization in canal wall down tympanoplasty with soft-wall reconstruction. Arch Otolaryngol Head Neck Surg 134: 652-657, 2008. 
25. Nadol JB Jr: Causes of failure of mastoidectomy for chronic otitis media. Laryngoscope 95: 410-413, 1985.

26. Prasanna Kumar S, Ravikumar A and Somu L: Modified radical mastoidectomy: A relook at the surgical pitfalls. Indian J Otolaryngol Head Neck Surg 65 (Suppl 3): S548-S552, 2013.

27. Pareschi R, Lepera D and Nucci R: Canal wall down approach for Tympano-mastoid cholesteatoma: Long-term results and prognostic factors. Acta Otorhinolaryngol Ital 39: 122-129, 2019.

28. Vartiainen E: Ten-year results of canal wall down mastoidectomy for acquired cholesteatoma. Auris Nasus Larynx 27: 227-229, 2000.
29. Blanco P, González F, Holguín J and Guerra C: Surgical management of middle ear cholesteatoma and reconstruction at the same time. Colomb Med (Cali) 45: 127-131, 2014

30. Lin JW and Oghalai JS: Can radiologic imaging replace second-look procedures for cholesteatoma. Laryngoscope 121: 4-5, 2011.

(c) (i) $\Theta$ This work is licensed under a Creative Commons EY NG NO Attribution-NonCommercial-NoDerivatives 4.0 International (CC BY-NC-ND 4.0) License. 